\title{
Plastic anisotropy of soft reconstituted clays
}

\author{
Minna Karstunen and Mirva Koskinen
}

\begin{abstract}
The aim of the paper is to extend the experimental validation of the S-CLAY1 model, which is a recently proposed elastoplastic constitutive model that accounts for initial and plastic strain-induced anisotropy. Drained stress path controlled tests were performed on reconstituted samples of four Finnish clays to study the effects of anisotropy in the absence of the complexities of structure present in natural undisturbed clays. Each test involved several loading, unloading, and reloading stages with different values of stress ratio and, hence, induced noticeable changes in the fabric anisotropy. Comparisons between test results and model predictions with the S-CLAY1 model and the modified Cam clay model demonstrate that despite its simplicity, the S-CLAY1 model can provide excellent predictions of the behaviour of unstructured soil.

Key words: soft clay, plastic anisotropy, bonding, reconstitution, stress-strain behaviour.

Résumé : Le but de cet article est d'élargir la validation expérimentale du modèle «S-CLAY1 », qui est un modèle de comportement élasto-plastique proposé récemment et qui tient compte de l'anisotropie initiale et plastique induite par la déformation. On a réalisé des essais drainés à cheminement de contrainte contrôlé sur des échantillons reconstitués de quatre argiles finlandaises pour étudier les effets de l'anisotropie en l'absence des complexités de la structure présente dans les argiles naturelles intactes. Chaque essai comprenait plusieurs stades de chargement, déchargement et rechargement avec différentes valeurs de rapport de contraintes et induisant ainsi des changements notables dans la fabrique de l'anisotropie. Des comparaisons des résultats d'essais et des prédictions de modèles avec le modèle « S-CLAY1 » et le modèle « Cam clay » modifié démontrent que, en dépit de sa simplicité, le modèle «S-CLAY1 » peut fournir d'excellentes prédictions du comportement du sol non structuré.
\end{abstract}

Mots-clés : argile molle, anisotropie plastique, liens, reconstitution, comportement-contrainte déformation.

[Traduit par la Rédaction]

\section{Background}

The arrangement of particles and particle contacts of most natural clays, referred to as the fabric, is initially anisotropic because of the platy shape of the clay particles, deposition process, and subsequent consolidation history of the deposit. Any subsequent loading, which induces plastic straining, will cause changes of the internal structure of the clay and, therefore, the initial anisotropy is modified. This phenomenon is called plastic strain-induced anisotropy. The initial and plastic strain-induced anisotropy have a significant impact on mechanical behaviour of soft clays, even though most constitutive models used for geotechnical design describe the soil as isotropic.

Since the 1980s, numerous constitutive models that account for plastic anisotropy have been proposed. A common way of describing initial anisotropy in a standard elastoplastic framework is to adopt an inclined yield surface. The changes in anisotropy due to plastic straining are represented by changes in the inclination (or position) of the yield surface according to so-called rotational or kinematic (translational) hardening laws. In these hardening laws, the changes in the anisotropy are commonly assumed to be caused by either plastic volumetric strains only (e.g., Banerjee and Yousif 1986; Dafalias 1986; Davies and Newson 1993; Whittle and Kavvadas 1994) or plastic shear strains only (e.g., Nova 1985; Banerjee et al. 1988). However, both plastic volumetric strains and plastic shear strains are changing the arrangement of particles and particle contacts, and consequently are likely to contribute to the evolution of anisotropy. This was appreciated for example by Pestana and Whittle (1999). The Pestana and Whittle model is rather complex, however, as it accounts for small-strain nonlinearity and hysteresis, etc., and requires considerable nonstandard testing for parameter determination. These features are not that important for lightly overconsolidated or normally consolidated clays, and consequently there is a need for simple anisotropic models, such as those proposed by Wheeler et al. (2003) and Dafalias et al. (2006). Furthermore, in many of the models, the hardening laws have not been systematically validated.

The relatively simple elastoplastic anisotropic model by Wheeler et al. (2003) is called S-CLAY1. It is an extension to the critical state models and involves an inclined yield surface. The evolution of plastic anisotropy is described with a rotational hardening law, in which all plastic strains are assumed to contribute to the development, modification, and erasure of anisotropy. The latter is a feature of the model that is a major improvement over some of the previous 
proposals. Furthermore, unlike in the Dafalias et al. (2006) model, an associated flow rule is assumed. The rotational hardening law in the S-CLAY1 model was developed based on an extensive experimental programme of drained stress path controlled triaxial tests on natural Otaniemi clay from southern Finland.

An additional benefit of the S-CLAY1 model compared to the isotropic modified Cam clay (MCC) model is that when the values for the state variables corresponding to the in situ conditions are defined according to the methodology proposed by Wheeler et al. (2003), the model gives good predictions for the normally consolidated value of $K_{0}$ when combined with the simple associated flow rule, where $K_{0}$ is the coefficient of earth pressure at rest. In many other proposals (e.g., Banerjee and Yousif 1986; Davies and Newson 1993; Dafalias et al. 2006) a nonassociated flow rule had to be adopted to yield sensible $K_{0}$ predictions and (or) proper predictions of critical state. Although, ideally, specialized testing is needed to calibrate the model parameter controlling the rate of yield surface rotation, a good estimate can be obtained using a simple empirical relation. Because the application of the S-CLAY1 model does not necessarily require any additional soil testing compared to the application of the MCC model (Roscoe and Burland 1968), it has great potential for practical use. Because of this feature, SCLAY1 has been adopted as a basis for a number of anisotropic creep models such as those of Vermeer et al. (2006); Zhou et al. (2006); and Huang and Wei (2007).

Even though the S-CLAY1 model was observed to perform significantly better on natural clays than the MCC model, some discrepancies were noticed (see Wheeler et al. 2003). These were thought to result from the effect of natural interparticle bonding and the degradation of the bonds due to subsequent straining, called destructuration. This phenomenon is demonstrated by an apparent stress path dependence of the slope of the normal compression line in the $\ln p^{\prime}-v$ space (where $p^{\prime}$ is the mean effective stress, and $v$ is the specific volume), as shown by Koskinen and Karstunen (2004) for several soft natural clays. This finding led the research in two distinct directions. On the one hand there was a need to study anisotropy in the absence of bonding (i.e., the effect of anisotropy on reconstituted clays) and on the other hand there was a need to incorporate the effect of bonding and destructuration into an anisotropic model. This paper deals with the former and some initial ideas on the latter have been presented in Koskinen et al. (2002a) and Karstunen and Koskinen (2004a).

The aim of this paper is to investigate the plastic anisotropy of reconstituted soft clays and hence provide further experimental validation for the S-CLAY1 model. A series of drained stress path controlled triaxial tests on reconstituted clays was designed. Four natural clays were chosen for testing materials: Murro clay, POKO clay, Otaniemi clay, and Vanttila clay. These clays cover a variety of soft Finnish (and Scandinavian) clays from moderately sensitive silty clays to extremely sensitive clays with a high clay mineral content. The key features of the S-CLAY1 model are described briefly. The test series are then presented and the results are compared with the S-CLAY1 model predictions. For comparison, equivalent simulations are made with the MCC model.

\section{The S-CLAY1 model}

The yield surface of S-CLAY1 in a principal stress space is a sheared ellipsoid, as shown in Fig. $1 a$ and cannot be presented solely using invariants. However, for comparison of model simulations with triaxial test data it is helpful to present the S-CLAY1 model using stress invariants $p^{\prime}$ (mean effective stress) and $q$ (deviator stress). This is only possible for a special case involving cross-anisotropic samples with their main axis of anisotropy aligned with the axial direction in a triaxial cell. In this special case, the amount of anisotropy can be expressed with a scalar parameter $\alpha$ describing the inclination of the yield curve (Fig. 1b). In this special situation, the S-CLAY1 yield surface equation is identical to that proposed by Dafalias (1986):

$$
\text { [1] } f=\left(q-\alpha p^{\prime}\right)^{2}-\left(M^{2}-\alpha^{2}\right)\left(p_{\mathrm{m}}^{\prime}-p^{\prime}\right) p^{\prime}=0
$$

where $M$ is the value of the stress ratio $\eta=q / p^{\prime}$ at critical state and $p_{\mathrm{m}}^{\prime}$ defines the size of the yield curve. The model hence involves two state variables that relate to the shape and size of the yield surface, namely $\alpha$ and $p_{\mathrm{m}}^{\prime}$.

Under general stress states, invariants cannot be used and anisotropy has to be expressed with a dimensionless second order tensor, referred to as a fabric tensor. The basic principles for the generalization of the model can be found in Wheeler et al. (2003) and Karstunen et al. (2005). For general stress states, including rotation of principal stress directions, the principal directions of the stress tensor and the fabric tensor do not necessarily coincide.

It is possible to assume different values of $M$ for triaxial compression and extension (Lode angle dependency), as discussed in Wheeler et al. (2003). Experimental data for soft clays on this issue are inconclusive, and the interpretation of the data is very subjective due to membrane effects, etc. For example, according to some authors the critical state stress ratios in triaxial compression are almost identical to those in triaxial extension (e.g., Atkinson et al. 1987), whereas the data of Kirkgard and Lade (1993) suggest significant Lode angle dependency. There are few data on the influence of the Lode angle on the prefailure stress-strain behaviour. While it would be preferable to incorporate Lode angle dependency for modelling problems that involve failure in drained conditions, an anisotropic model such as SCLAY1 predicts very realistic undrained shear strengths in triaxial extension, even if the critical state friction angle in extension can be very high for high values of $M$ when assuming constant $M$ (Drucker-Prager). For the clays considered, no data on failure in triaxial extension are available. Furthermore, none of the simulations shown here relate to failure. For the sake of simplicity, it has been assumed that the triaxial compression value of $M$ is used throughout. The results of model simulations show that this has been a reasonable assumption.

The S-CLAY1 model is intended for use with normally consolidated or lightly overconsolidated soft clays. Therefore, plastic strains are assumed to dominate, and for simplicity, the elastic behaviour is described with the same isotropic relationship as in the MCC model, requiring the values for two soil parameters; namely the slope $\kappa$ of the swelling lines in the $\ln p^{\prime}-v$ plane and the elastic shear 
Fig. 1. The S-CLAY1 yield surface: (a) three-dimensional stress space (for $\tau_{x y}=\tau_{y z}=\tau_{z x}=0$ and $\alpha_{x y}=\alpha_{y z}=\alpha_{z x}=0$ ); $(b)$ triaxial stress space (for $\sigma_{x}{ }^{\prime}=\sigma_{z}^{\prime} \tau_{x y}=\tau_{\mathrm{yz}}=0, \alpha_{x}=\alpha_{z}$, and $\alpha_{x y}=\alpha_{y z}=\alpha_{z x}=0$ ).
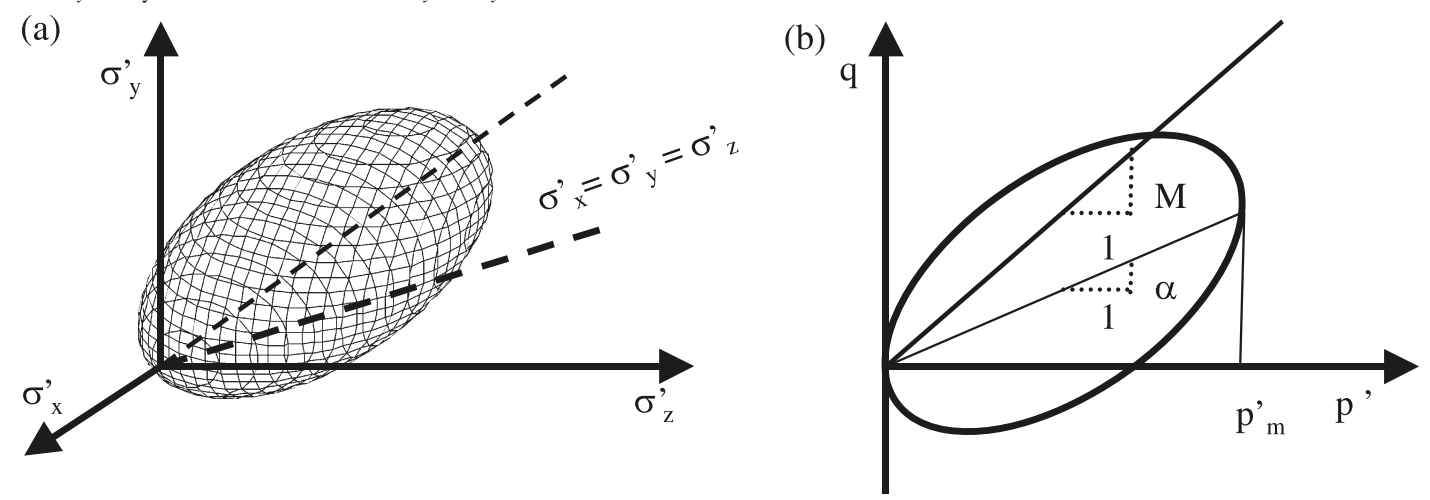

modulus $G^{\prime}$. Alternatively, the Poisson's ratio, $v^{\prime}$ can be used instead of $G^{\prime}$.

The S-CLAY1 model incorporates two hardening laws. The first law, which is the same as that in the MCC model, describes changes in the size of the yield curve caused by increments of plastic volumetric strain $\mathrm{d} \varepsilon_{\mathrm{v}}^{\mathrm{p}}$ :

$$
\text { [2] } \quad \mathrm{d} p_{\mathrm{m}}^{\prime}=\frac{\nu p_{\mathrm{m}}^{\prime}}{\lambda-\kappa} \mathrm{d} \varepsilon_{\mathrm{v}}^{\mathrm{p}}
$$

where $\lambda$ is the slope of the normal compression line in the $\ln p$ ' $-v$ plane. The second hardening law concerns changes in the inclination of the yield curve caused by increments of plastic volumetric strain and plastic shear strain $\left(\mathrm{d} \varepsilon_{\mathrm{d}}^{\mathrm{p}}\right)$ :

[3] $\mathrm{d} \alpha=\mu\left[\left(\frac{3 \eta}{4}-\alpha\right)\left\langle\mathrm{d} \varepsilon_{\mathrm{v}}^{\mathrm{p}}\right\rangle+\beta\left(\frac{\eta}{3}-\alpha\right)\left|\mathrm{d} \varepsilon_{\mathrm{d}}^{\mathrm{p}}\right|\right]$

where the soil parameter $\mu$ controls the absolute rate at which the yield curve rotates towards its current target value that depends on the stress ratio $\eta\left(=q / p^{\prime}\right)$; and the parameter $\beta$ is the relative effectiveness of volumetric and shear strains in rotating the yield curve. The second hardening law was developed based on a systematic series of drained stress-controlled triaxial tests on Otaniemi clay, involving over 20 special triaxial tests, as described in Wheeler et al. (2003). The Macaulay brackets ensure that the model predictions are sensible on the dry side of the critical state, when the increment of plastic volumetric strains is negative (see Wheeler et al. 2003 for details).

An associated flow rule, when combined with the inclined S-CLAY1 yield curve, has been shown to be a reasonable assumption for some reconstituted soft clays (Koskinen et al. 2002b; Karstunen and Koskinen 2004a). Due to the rotation of the yield surface at the onset of plastic straining, it is not possible to test for the validity of the flow rule by plotting increments of plastic strains against a yield surface. The true test for the flow rule for a given yield surface formulation and elastic law is a comparison of the pattern of straining observed in a test (strain path) versus that in a corresponding model simulation.

The use of the S-CLAY1 model requires values for four conventional soil constants $\left(\kappa, \lambda, \nu^{\prime}\right.$, and $\left.M\right)$ as in $\mathrm{MCC}$, plus values for the two additional soil constants $\beta$ and $\mu$ associated with rotational hardening. In addition, the description of the initial state of the soil requires initial values

Table 1. Mineralogical composition (\%) of the test materials.

\begin{tabular}{llll}
\hline & $\begin{array}{l}\text { Murro } \\
\text { clay }\end{array}$ & $\begin{array}{l}\text { Otaniemi } \\
\text { clay }\end{array}$ & $\begin{array}{l}\text { Vanttila } \\
\text { clay }\end{array}$ \\
\hline Quartz & 23 & 13 & 18 \\
Feldspar & 46 & 42 & 33 \\
\multicolumn{2}{l}{ Clay minerals } & & \\
Illite & 15 & 20 & 29 \\
Chlorite & 10 & 16 & 11 \\
Kaolinite & 5 & 8 & 8 \\
\hline
\end{tabular}

Note: Data for Murro clay and Otaniemi clay from Messerklinger et al. (2003); data for Vanttila clay from Messerklinger (S. Messerklinger, personal communication, 2002. Based on Internal Report J391, Institute for Global Engineering, Swiss Federal Institute of Technology, Zurich.)

for the state variables $\alpha, p_{\mathrm{m}}^{\prime}$, and $e$ (void ratio). The values for the soil constants and the initial values of the state parameters can be determined from the results of a standard triaxial shear test and an oedometer test. The application of the model does not, therefore, require any nonstandard testing, although stress path controlled tests, such as those presented in this paper, can be used to optimize the value for the parameter $\mu$.

\section{Materials and test programme}

\section{Description of materials}

Four Finnish clays were chosen for testing materials, namely Murro clay, POKO clay, Otaniemi clay, and Vanttila clay. The results from POKO clay were shown in Koskinen et al. (2002a and 2002b), and, thus, not presented here. Natural clays were selected, rather than a material such as kaolin clay, so that the behaviour of the clays in reconstituted state can ultimately be compared with that of the corresponding natural clays. The availability of material, and the time taken for the tests (each test shown has taken about 2 3 months), affected the number of tests that could be made. Most Scandinavian clay deposits are either lightly overconsolidated or normally consolidated relatively young postglacial clays that have sedimented in alternating conditions of fresh and salt water depending on the evolutionary stages of the Baltic Sea. 
Table 2. Properties of the test materials.

\begin{tabular}{|c|c|c|c|c|c|c|}
\hline & \multicolumn{2}{|c|}{ Murro clay } & \multicolumn{2}{|c|}{ Otaniemi clay } & \multicolumn{2}{|c|}{ Vanttila clay } \\
\hline & Natural & Reconstituted & Natural & Reconstituted & Natural & Reconstituted \\
\hline Depth (m) & $7.0-7.5$ & $6.9-7.6$ & $4.0-4.7$ & $4.0-4.4$ & $2.4-3.1$ & $2.7-2.9$ \\
\hline Water content $(\%)$ & 77 & 76 & 100 & 83 & 118 & 91 \\
\hline Liquid limit $(\%)$ & 88 & - & 95 & - & 98 & - \\
\hline Plasticity index & 55 & - & 66 & - & 68 & - \\
\hline Particles $<0.002 \mathrm{~mm}(\%)$ & 30 & 30 & 78 & 78 & 51 & 51 \\
\hline Organic content $(\%)$ & 2.4 & 2.4 & 0.4 & 0.4 & 1.9 & 1.9 \\
\hline Specific gravity & 2.66 & 2.66 & 2.80 & 2.80 & 2.74 & 2.74 \\
\hline Undrained shear strength, fall cone test, $(\mathrm{kPa})$ & 26 & 6 & 7 & 6 & 8 & 11 \\
\hline Sensitivity & 10.5 & - & 9 & - & $>50$ & - \\
\hline
\end{tabular}

The mineralogical compositions of Murro, Otaniemi, and Vanttila clays, determined at the Swiss Federal Institute of Technology (ETH Zurich) were shown in Table 1. Otaniemi clay contains the smallest amount of quartz and has a rather high clay mineral content, in contrast to Murro clay, which can be classified as a silty clay (or clayey silt). Vanttila clay has the highest clay mineral content, and the main clay mineral in all clays studied is illite.

Some typical properties of the three clays are presented in Table 2, corresponding to both their natural and reconstituted states. There is significant variation in the basic properties, which is typical of Finnish clays. All clays exhibit some real or apparent bonding in their natural state as demonstrated by the sensitivity values shown in Table 2 . The undrained shear strengths of the natural clays, measured with a fall cone test, are very low. The water content of reconstituted Murro clay corresponds to the water content of the natural clay. Due to the high natural water contents of Otaniemi and Vanttila clays, however, it was not possible to prepare reconstituted samples at the same water content as that of the natural samples: the samples would have simply been too soft to be handled and tested. All the reconstituted samples were tested at an initial water content of $80 \%-90 \%$.

Murro clay is a silty clay from a rather homogenous deposit near the western coast of Finland and located just outside the town of Seinäjoki (Fig. 2). The percentage of the clay-sized fraction of Murro clay is $30 \%$, which consists of clay minerals only (Table 1). A further distinguishing feature is that Murro clay is very rich in sulphur, which gives it a black colour.

Otaniemi clay is from a deposit on the shore of the Gulf of Finland in the city of Espoo (Fig. 2). It has a rather high claysized fraction of about $78 \%$, and the water content is significantly higher than the liquid limit. The sensitivity of Murro and Otaniemi clays varies between 9 and 12, and so in a global context they can be regarded as moderately sensitive.

Vanttila clay from Espoo has the highest natural water content of the three clays considered, namely $118 \%$, which is $20 \%$ over the liquid limit. Consequently, Vanttila clay is highly sensitive, and, in fact, its remoulded strength was not measurable. In reconstituting the clay, Vanttila clay was remoulded to a slurry at its natural water content, and no water was added.

\section{Test procedure}

The triaxial testing programme for reconstituted clay samples was carried out at Helsinki University of Technology
Fig. 2. Location of sampling sites.

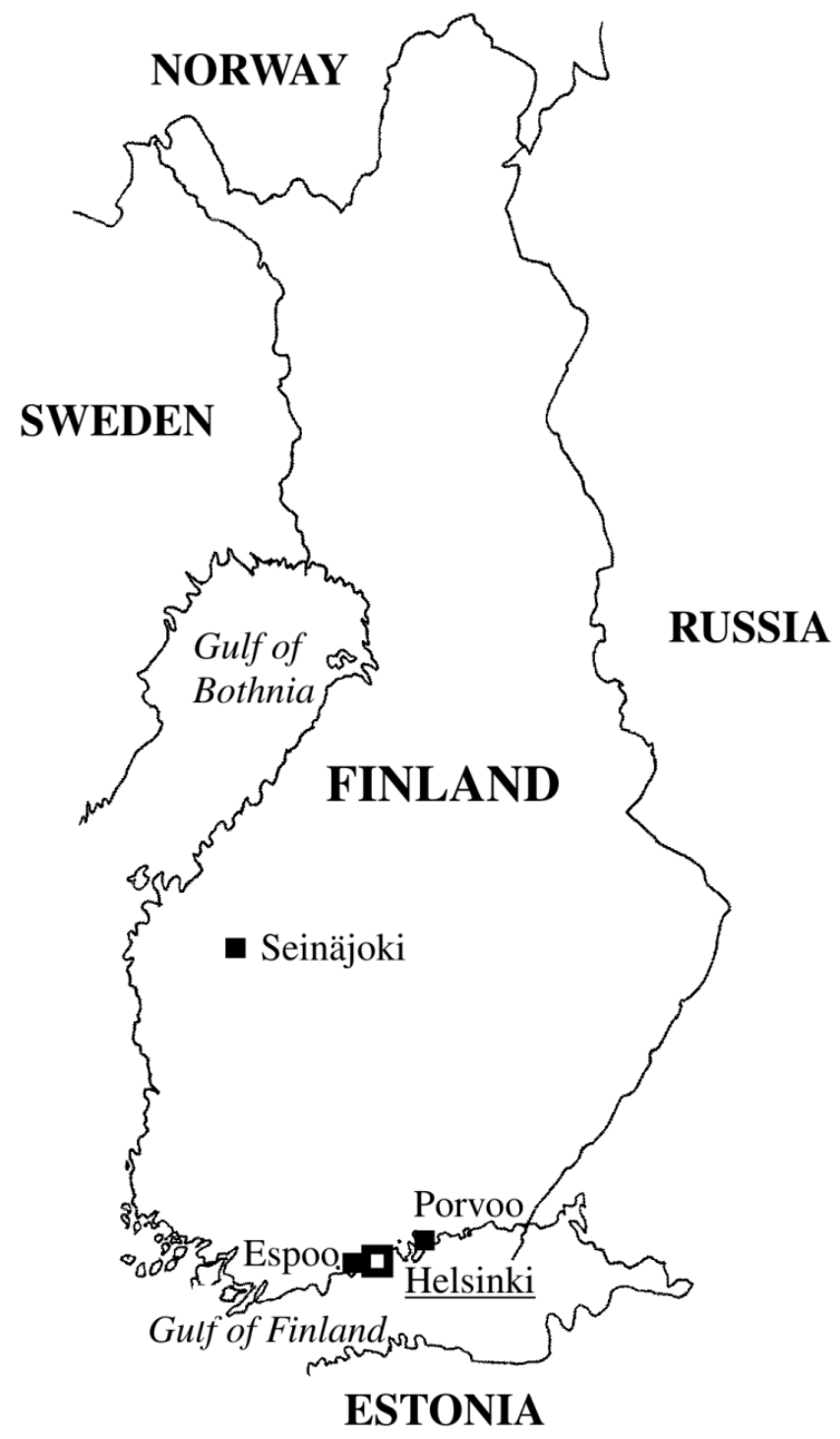

and was designed in collaboration with the researchers in Glasgow. According to Burland (1990), reconstitution is the remoulding of a natural clay sample thoroughly at a water content of $w=w_{\mathrm{L}}$ to $1.5 w_{\mathrm{L}}$ where $w_{\mathrm{L}}$ is the liquid limit and then consolidating it one-dimensionally. In this study, the remoulding was done with a standard food mixer, where the 
required amount of distilled water was added during the mixing until the slurry was in liquid form. The use of distilled water might have an effect on the behaviour of the samples, but it is not considered to be significant.

After mixing, the slurry was poured into an acrylic cylinder $5 \mathrm{~cm}$ in diameter and approximately $30 \mathrm{~cm}$ high and was consolidated one-dimensionally. Because of friction, the nominal load of $15 \mathrm{kPa}$ that was used for consolidation was not entirely transferred to the samples. The consolidation time varied from 3 weeks (for Murro clay) to 3 months (for Vanttila clay). The time was chosen based on Taylor's square root of time method, so the primary consolidation had ended for all samples before they were extruded from the cylinder. Immediately after extrusion, the samples were trimmed to a height of $100 \mathrm{~mm}$ and set up in a triaxial apparatus. Filter paper strips, placed around the circumference of the sample, provided radial drainage. Pore pressure was not measured during the tests to enable the water to drain from both the top and bottom of the samples. Preliminary triaxial tests with pore pressure measurement on Otaniemi clay and oedometer test results were used to determine the appropriate load rates.

The triaxial tests were drained incremental anisotropic stress controlled tests done using small stepwise loading. The increments of vertical and radial stress were applied manually with the drainage valve open. All samples of a given clay were first loaded along the same stress path, at a stress ratio $\eta_{0}$, to the same stress level $p^{\prime}{ }_{\text {max }}$ (see Table 3 ), to establish the same fabric and consolidation state for all samples of the particular clay. The values of $\eta_{0}$ were chosen based on preliminary estimates of the normally consolidated values of $K_{0}$, so that the initial anisotropic consolidation in the triaxial cell approximated one-dimensional consolidation. The intention was to produce reconstituted samples with a consolidation history similar to that of the natural samples. (The initial estimates of $K_{0}$ for all four clays were subsequently found to differ slightly from the final estimates of $K_{0}$. These were evaluated using Jaky's simplified formula from the results of drained and undrained triaxial shear tests (not presented in this paper). In Jaky's formula critical state friction angles were used rather than peak friction angles, as the latter depends for example on anisotropy). The measured radial strains during $\eta_{0}$ loading were small, but nontrivial, of the order of $2 \%-4 \%$. Subsequently, after the initial consolidation stage, the samples were unloaded with the same stress ratio $\eta_{0}$ to a mean effective stress $p^{\prime}$ of 6-12 $\mathrm{kPa}$.

After unloading, two loading-unloading cycles were carried out with constant stress ratios $\eta_{1}$ and $\eta_{2}$, referred to in the following as the first and second loading stages, to the values of mean effective stress listed in Table 3 as $p^{\prime}{ }_{\text {max }}$ and $p_{2 \max }^{\prime}$, respectively. The unloading with $\eta_{1}$ was always done to $p^{\prime}=4-19 \mathrm{kPa}$, and with $\eta_{2}$ to $p^{\prime}=8-29 \mathrm{kPa}$. For each clay, the stress ratio $\eta_{1}$ differed test by test, to cover a wide range of stress paths for each clay, including stress probing in both triaxial compression and triaxial extension. The stress ratio $\eta_{2}$ for each test was chosen to differ significantly from the stress ratio $\eta_{1}$ of the same test, to cause significant evolution of anisotropy. With these arrangements, the effects of changes in fabric anisotropy on stress-strain behaviour could be studied. Each loading stage involved 10-20 load increments. The typical sizes for the load incre- ments are given in Table 4 for Murro, Otaniemi, and Vanttila clays. The duration of the load increments was typically $1 \mathrm{~d}$ during the weekdays and $3 \mathrm{~d}$ during the weekends in all loading stages, but was occasionally longer than that due to holiday periods. Axial strain - volumetric strain plots versus time confirmed that the specimens reached approximately full consolidation within $24 \mathrm{~h}$ with no major secondary consolidation. The maximum rate of volumetric strain was about $2.3 \%-2.9 \%$ per $24 \mathrm{~h}$ (for Vanttila clay). The modified secondary compression indices $\left(C_{\alpha \varepsilon}\right)$ for reconstituted Murro, Otaniemi, and Vanttila clays are 1.25, 1.23, and 1.34 , respectively, and these values are notably smaller than the corresponding values for the natural clays.

The test series presented in this paper are listed in Table 3. Four tests each were done on samples of reconstituted Murro and Otaniemi clays, and two tests were done on samples of reconstituted Vanttila clay. The initial void ratios $e_{0}$ in Table 3 correspond to the values measured when the samples were set up in the triaxial apparatus. Some variation in the initial void ratio can be observed for all materials. Generally, the void ratios are high and the scatter is greatest for Otaniemi clay. The variation of the initial void ratio for a given clay was probably partly due to variation in the friction between the piston and the acrylic cylinder during sample preparation in the mould. Furthermore, a slight variation in the intrinsic material properties is possible given that each batch was mixed to produce enough material for two moulds. In most cases, each cylinder produced only two samples, one for the oedometer test and one for the triaxial test. For a case where the mould yielded three samples (Otaniemi clay), the two oedometer samples trimmed from the top had void ratios of 2.241 and 2.177 , respectively, and the triaxial sample had a void ratio of 2.364 . Therefore, the variation of void ratio is not systematic.

\section{Parameter determination and initial state variables}

The procedure for determining soil parameter values and initial values of the state variables for the S-CLAY1 model is relatively straightforward, as explained by Wheeler et al. (2003), and for the sake of brevity is not discussed here in detail. The values for the parameters and initial state variables used for the simulations of the tests listed in the following sections are shown in Tables 5 and 6 . With the exception of the elastic parameters, the values for the soil constants have been derived totally independently of the tests described in this paper using oedometer and standard triaxial compression test results. Therefore, the values have not, in general, been calibrated to ensure a good match.

The slope of the intrinsic compression line, $\lambda$, for each clay was determined from oedometer tests on reconstituted samples, and the values of $\kappa$ and $v^{\prime}$ were estimated from the first unloading stages of the triaxial tests, assuming an elastic relationship. For Murro clay the critical state stress ratio $M$ was determined from drained triaxial tests on natural samples. The results of a series of undrained tests on natural samples were used as shown in Karstunen and Koskinen (2004b) for Otaniemi and Vanttila clays, however, because the shear strains required to reach critical states during drained shearing exceeded the range of the equipment (23\%). The values of $M$ in Table 5 correspond to friction angles of $32^{\circ}-39^{\circ}$, covering a reasonable range of friction 
Table 3. Tests on reconstituted Murro, Otaniemi, and Vanttila clays.

\begin{tabular}{|c|c|c|c|c|c|c|c|c|}
\hline Test No. & Depth (m) & $e_{0}$ & $\eta_{0}$ & $\begin{array}{l}p_{0 \max }^{\prime} \\
(\mathrm{kPa})\end{array}$ & $\eta_{1}$ & $\begin{array}{l}p_{1 \text { max }}^{\prime} \\
(\mathrm{kPa})\end{array}$ & $\eta_{2}$ & $\begin{array}{l}p_{2 \max }^{\prime} \\
(\mathrm{kPa})\end{array}$ \\
\hline \multicolumn{9}{|l|}{ Murro clay } \\
\hline CAD 3166R & $6.92-7.59$ & 2.078 & 0.99 & 31.7 & 0.21 & 108.0 & 0.92 & 244.0 \\
\hline CAD 3167R & $6.92-7.59$ & 1.957 & 0.99 & 31.7 & 1.23 & 74.9 & 0.10 & 259.0 \\
\hline CAE 3215R & $6.92-7.59$ & 1.990 & 0.99 & 31.6 & 0.75 & 93.4 & -0.41 & 140.0 \\
\hline CAE 3216R & $6.92-7.59$ & 1.969 & 0.98 & 31.5 & -0.62 & 70.4 & 0.60 & 188.0 \\
\hline \multicolumn{9}{|c|}{ Otaniemi clay } \\
\hline CAE 3516R & $4.15-4.37$ & 2.144 & 0.65 & 25.5 & 0.51 & 55.3 & -0.53 & 85.1 \\
\hline CAE 3519R & $4.15-4.37$ & 2.364 & 0.65 & 25.5 & -0.51 & 51.4 & 0.52 & 134.0 \\
\hline CAE 3819R & $4.00-4.37$ & 2.266 & 0.65 & 25.6 & -0.33 & 39.0 & 0.77 & 91.2 \\
\hline CAE 3820R & $4.00-4.37$ & 2.302 & 0.65 & 25.5 & 0.78 & 68.0 & -0.27 & 132.0 \\
\hline \multicolumn{9}{|l|}{ Vanttila clay } \\
\hline CAE 3427R & $2.65-2.91$ & 2.457 & 0.61 & 25.0 & -0.61 & 57.4 & 0.40 & 133.0 \\
\hline CAE 3428R & $2.65-2.91$ & 2.409 & 0.61 & 25.0 & 0.40 & 66.9 & -0.61 & 126.0 \\
\hline
\end{tabular}

Table 4. Typical load rates in tests on Murro, Otaniemi, and Vanttila clay.

\begin{tabular}{|c|c|c|c|c|c|c|c|c|c|}
\hline \multirow{2}{*}{$\begin{array}{l}\text { Load increment } \\
\text { Load stage }\end{array}$} & \multicolumn{3}{|c|}{$\Delta q_{\max }(\mathrm{kPa})$} & \multicolumn{3}{|c|}{$\Delta p_{\max }(\mathrm{kPa})$} & \multicolumn{3}{|c|}{$\Delta \sigma_{3 \max }(\mathrm{kPa})$} \\
\hline & 1 & 2 & 3 & 1 & 2 & 3 & 1 & 2 & 3 \\
\hline \multicolumn{10}{|l|}{ Murro clay } \\
\hline CAD 3166R & 5.7 & 2.5 & 27.5 & 4.7 & 10.8 & 28.9 & 3.0 & 10.0 & 20.0 \\
\hline CAD 3167R & 5.7 & 10.0 & 3.0 & 4.7 & 7.3 & 26.0 & 3.0 & 4.0 & 25.0 \\
\hline CAE 3215R & 5.7 & 10.4 & -6.4 & 4.6 & 13.5 & 13.3 & 3.0 & 10.0 & 15.0 \\
\hline CAE 3216R & 5.7 & -10.9 & 11.8 & 4.6 & 8.4 & 18.9 & 3.0 & 10.0 & 15.0 \\
\hline \multicolumn{10}{|l|}{ Otaniemi clay } \\
\hline CAE 3516R & 1.7 & 1.9 & -3.0 & 2.6 & 3.6 & 5.2 & 2.0 & 3.0 & 6.0 \\
\hline CAE 3519R & 1.7 & -2.0 & 4.5 & 2.6 & 3.9 & 8.5 & 2.0 & 4.5 & 7.0 \\
\hline CAE 3819R & 1.7 & -1.0 & 4.9 & 2.6 & 2.7 & 5.5 & 2.0 & 3.0 & 4.0 \\
\hline CAE 3820R & 1.7 & 5.6 & -4.2 & 2.6 & 6.8 & 9.1 & 2.0 & 5.0 & 10.0 \\
\hline \multicolumn{10}{|l|}{ Vanttila clay } \\
\hline CAE 3427R & 1.6 & -3.4 & 7.1 & 2.5 & 5.9 & 17.4 & 2.0 & 7.0 & 15.0 \\
\hline CAE 3429R & 1.5 & 3.2 & -9.1 & 2.5 & 8.1 & 16.2 & 2.0 & 7.0 & 19.0 \\
\hline
\end{tabular}

Note: $\Delta p_{\max }$, maximum increment of mean effective stress; $\Delta q_{\max }$, maximum increment of deviator stress; $\Delta \sigma_{3 \max }$ maximum increment of cell pressure.

angles for soft clays. The results of the triaxial shear tests were conducted on natural samples, A drained triaxial shear test on a reconstituted sample of Vanttila clay confirmed that the stress ratios at critical state are similar to those for natural and reconstituted samples.

The values for $\mu$ in Table 5 were estimated based on empirical formula by Zentar et al. (2002). The tests were designed to involve considerable yield curve rotation so that the effect of $\mu$ value could be investigated. The results, as presented in the next section (see Fig. 5) seem to show that the estimate is appropriate. The value of $\beta$ was estimated using normally consolidated $K_{0}$ values, as explained in Wheeler et al. (2003) and hence can be calculated when the friction angle at critical state is known.

Because the amount of friction in the mould was unknown, different samples of the same clay may have had slightly different stress histories at the start of the tests. Therefore, the numerical model simulations were started at the beginning of the loading stage with $\eta_{1}$, when all samples of a given clay had experienced the same stress history (i.e., loading at a stress ratio $\eta_{0}$ to the mean effective stress of $p_{\text {(max }}^{\prime}$ ) (as listed in Table 3), followed by unloading.
The size and inclination of the initial yield curve, created by the initial loading at $\eta_{0}$, had to be defined as input. The initial inclinations of the yield curves $\alpha_{0}$ were assumed to correspond to the target values (for loading at $\eta_{0}$ ) predicted by the S-CLAY1 model. The target values can be calculated by letting $\mathrm{d} \alpha=0$ in eq. [3] and combining this with the flow rule. This leads to a quadratic equation for $\alpha$ (Wheeler et al. 2003):

$$
\text { [4] } 3(3 \eta-4 \alpha)\left(M^{2}-\eta^{2}\right)= \pm 8 \beta(3 \alpha-\eta)(\eta-\alpha)
$$

where a positive sign applies for triaxial compression $(\eta \geq$ 0 ) and a negative sign applies for triaxial extension $(\eta \leq 0)$.

The sizes of the yield curves $p_{\text {m0 }}^{\prime}$ (in Table 5) were determined by fitting the yield curve equation (eq. [1]) through the maximum stress point of the loading stages with $\eta_{0}$ (shown with open triangles in Fig. 3), using the independently derived values of $M$ and $\alpha_{0}$ for defining the shape of the curve. To check how well this assumption fits with experimental data, the yield points from the loading stage with $\eta_{1}$ (shown in Fig. 3 as solid circles) were determined from linear stress-strain plots using a bilinear construction, 
Table 5. Values for the parameters and intitial state variables used in the simulations.

\begin{tabular}{lllllllll}
\hline Model & $\lambda$ & $\kappa$ & $\nu^{\prime}$ & $M$ & $\mu$ & $\beta$ & $\alpha_{0}$ & $p_{\mathrm{m} 0}^{\prime}(\mathrm{kPa})$ \\
\hline Murro clay & & & & & & & & \\
MCC & 0.21 & 0.034 & 0.30 & 1.60 & - & - & - & 44.5 \\
S-CLAY1 & 0.21 & 0.034 & 0.30 & 1.60 & 20 & 1.02 & 0.46 & 35.5 \\
Otaniemi clay & & & & & & & & \\
MCC & 0.26 & 0.040 & 0.25 & 1.30 & - & - & - & 33.0 \\
S-CLAY1 & 0.26 & 0.040 & 0.25 & 1.30 & 20 & 0.86 & 0.42 & 26.0 \\
Vanttila clay & & & & & & & & \\
MCC & 0.30 & 0.057 & 0.20 & 1.35 & - & - & - & 32.3 \\
S-CLAY1 & 0.30 & 0.057 & 0.20 & 1.35 & 15 & 0.91 & 0.40 & 26.0 \\
\hline
\end{tabular}

as demonstrated in Fig. 4 where $\varepsilon_{\mathrm{v}}$ is volumetric strain and $\varepsilon_{1}$ is axial strain. The longer than desired duration of some load steps has been taken into account in the interpretation of the results. According to Koskinen et al. (2003), this methodology yields rather similar yield points from different stress-strain plots even for tests that involve a considerable yield curve rotation. However, the methodology isbest suited for natural soft soils, for which the yielding is very sudden and distinct, even for stress paths inducing yield curve rotation due to the effect of destructuration. Any yield points for reconstituted soils from tests that involve notable changes in anisotropy always need to be viewed with caution. In Fig. 3, the theoretical yield curve is shown together with the experimental yield points for the four clays. For the sake of completeness, the yield curve for POKO clay is included in Fig. 3. The experimental yield points in Fig. 3 seem to match well with the theoretical yield curve, in particular for POKO, Otaniemi, and Vanttila clays. For subsequent loading stages the yield points were not determined directly, as the model simulations enable direct visual comparison between the predicted yield and the experimental results.

The S-CLAY1 model reduces to the MCC model by setting the values of $\mu, \beta$, and $\alpha_{0}$ to zero. The size of the yield curve $p_{\mathrm{m} 0}^{\prime}$ for MCC was defined so that the yield curves for both models coincided at the stress ratio corresponding to the estimated $\eta_{\mathrm{K} 0}$ line., where $\eta_{\mathrm{K} 0}$ is the stress ratio corresponding to one-dimensional deformation.

\section{Test results and model simulations}

All tests on reconstituted clay samples listed in Table 3 were simulated with the S-CLAY1 and MCC models. The initial stresses $\left(p_{0}^{\prime}\right.$ and $\left.q_{0}\right)$ and the initial void ratio for the simulations $\left(e_{0 \text { sim }}\right)$, listed in Table 6 for each test, were chosen to correspond to an observed data point at the beginning of the loading stage with $\eta_{1}$ in each test. Experimental measurements of strain were defined relative to this starting point to allow comparison with the model predictions. In the following, all results have been plotted in terms of true strains rather than engineering strains to be consistent with the model simulations.

\section{Effect of rate of yield curve rotation, $\mu$}

According to Wheeler et al. (2003), the model simulations are not particularly sensitive to the value of parameter $\mu$ unless the loading involves a major change in the stress path direction. Test CAE 3216R on Murro clay has been chosen
Table 6. Initial void ratio and stress state variables used in the simulations.

\begin{tabular}{lccc}
\hline Test No. & $e_{0 \text { sim }}$ & $q_{0}(\mathrm{kPa})$ & $p_{0}^{\prime}(\mathrm{kPa})$ \\
\hline Murro clay & & & \\
CAD 3166R & 1.503 & 1.8 & 8.6 \\
CAD 3167R & 1.435 & 16.7 & 13.6 \\
CAE 3215R & 1.561 & 7.9 & 10.6 \\
CAE 3216R & 1.521 & -6.1 & 10.0 \\
Otaniemi clay & & & \\
CAE 3516R & 1.758 & 4.9 & 9.6 \\
CAE 3519R & 1.837 & -4.3 & 8.6 \\
CAE 3819R & 1.802 & -2.1 & 6.8 \\
CAE 3820R & 1.817 & 4.9 & 6.6 \\
Vanttila clay & & & \\
CAE 3427R & 2.063 & -4.0 & 6.7 \\
CAE 3428R & 1.970 & 3.7 & 9.2 \\
\hline
\end{tabular}

for demonstrating the effect of $\mu$. This test involves maximal yield curve rotation, i.e., it is the test where the impact of $\mu$ is most obvious. The stress ratio in the first loading stage is negative and, therefore, very different from the $K_{0}$ stress ratio. Therefore, a great deal of yield curve rotation would be expected. It should be noted that this is an extreme case, and it is unlikely to represent any loading that would typically occur in practical situations. The test was simulated with the S-CLAY1 model using three different values for $\mu$.

In Fig. 5, test CAE 3216R on reconstituted Murro clay is shown together with the S-CLAY1 model simulations using three different $\mu$ values. The $\mu$ value has only a small effect on the magnitude of predicted volumetric strains (Fig. $5 a$ ). However, the curvature of the normally consolidated part of the volumetric stress-strain curve increases with an increase in the $\mu$ value, furthermore, the amount of volumetric strains is slightly lower for the lower value of $\mu$ than for the higher $\mu$ values. The effect of $\mu$ is more significant on the shear strains (Fig. 5b) than on the volumetric strains. The magnitude of the shear strains decreases when the $\mu$ value increases. The strains paths (Fig. 5c) are naturally also affected by the $\mu$ value. All tests on reconstituted Murro clay were simulated in a similar manner. The value $\mu=20$, shown in Table 5, that was chosen to be most appropriate for Murro clay does not appear to give the best match for this particular test. Nevertheless, the simulations shown in this paper and by Karstunen and Koskinen (2004a), all using $\mu=20$, give excellent predictions for most tests. 
Fig. 3. Initial yield curves for reconstituted clays: (a) Murro clay; (b) POKO clay; (c) Otaniemi clay; (d) Vanttila clay.
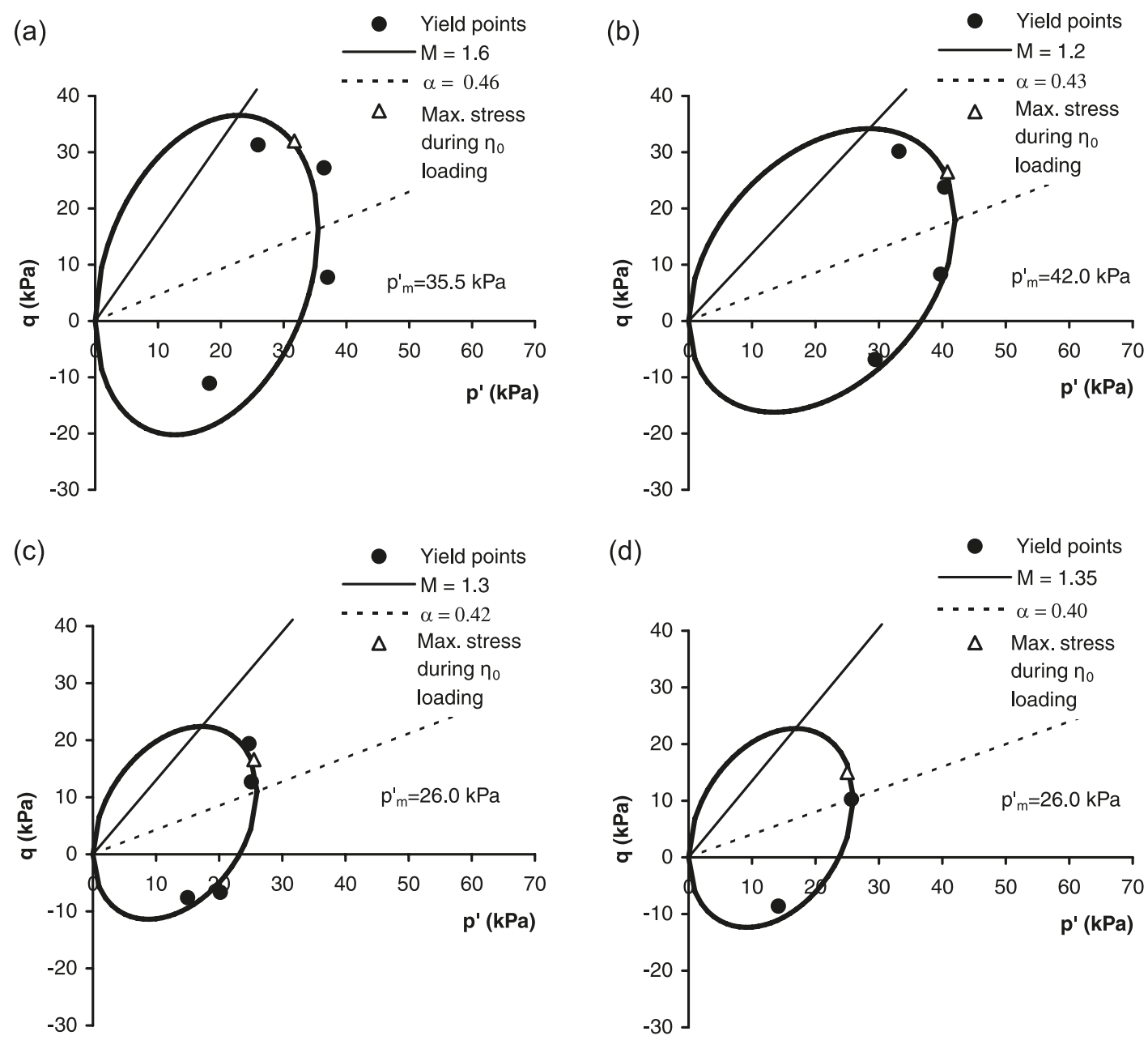

All of the tests on all four clays were simulated in a similar manner using different values of $\mu$. The values given in Table 5 correspond to the empirical formulation by Zentar et al. (2002), which suggests that $\mu$ values are typically between $10 / \lambda$ and $20 / \lambda$, where $\lambda$ is the slope of the apparent normal compression line for natural samples. Based on experience with these four very different clays, the empirical formulation gives an estimate of the $\mu$ value that is good enough for practical purposes. The stress paths in practical loading situations are usually such that the predicted response is not particularly sensitive to the $\mu$ value.

\section{Tests on reconstituted Murro clay}

Test CAE 3215R, which is shown in Fig. 6 together with the model simulations involved a first loading stage in compression $\left(\eta_{1}=0.75\right)$, after which the sample was first unloaded and then reloaded in triaxial extension $\left(\eta_{2}=-0.42\right)$. In the first loading stage, the volumetric strains (Fig. 6a) and shear strains (Fig. 6b) are predicted reasonably well with S-CLAY1, whereas MCC significantly overpredicts the shear strains. Both models underpredict the volumetric strains and overestimate the yield stress in the second loading stage. S-CLAY1, however, performs slightly better than MCC in both stages. The pattern of straining is estimated reasonably well with S-CLAY1, in contrast to MCC.

The results for tests CAE 3215R, CAD 3166R, and CAE 3216R included in Karstunen and Koskinen (2004a) show a match that is similar to that of the S-CLAY1 simulations and the experimental data. The overall performance of $\mathrm{S}$ CLAY1 in all tests on reconstituted Murro clay is reasonably good and is a significant improvement over the performance of MCC. In particular, the yield stress and shear strain predictions of S-CLAY1 are superior to those of MCC. Some of the discrepancies in volumetric strain prediction may be attributed to the creep effects, as in some tests the duration of loading was not always constant.

\section{Tests on reconstituted Otaniemi clay}

The results for test CAE 3516R are presented in Fig. 7. In this test, MCC gives a marginally better prediction of volumetric strains than S-CLAY1 (Fig. 7a) during the first loading stage, because MCC predicts the yield point slightly better than S-CLAY1. However, yielding in the second loading stage is predicted much better by S-CLAY1 than MCC, because S-CLAY1 can account for the changes in anisotropy due to the first loading. Furthermore, due to the radical change in the stress path direction from stage 1 to stage 2 $(0.51$ to -0.53$)$, the onset of yielding in the experiments appears to be very gradual, and this is captured by S-CLAY1. Hence, the shape of the stress-strain curve is much better 
Fig. 4. Determination of yield points from the first loading stage in test CAE $3820 \mathrm{R}$ on reconstituted Otaniemi clay. $\varepsilon_{\mathrm{v}}$, volumetric strain.
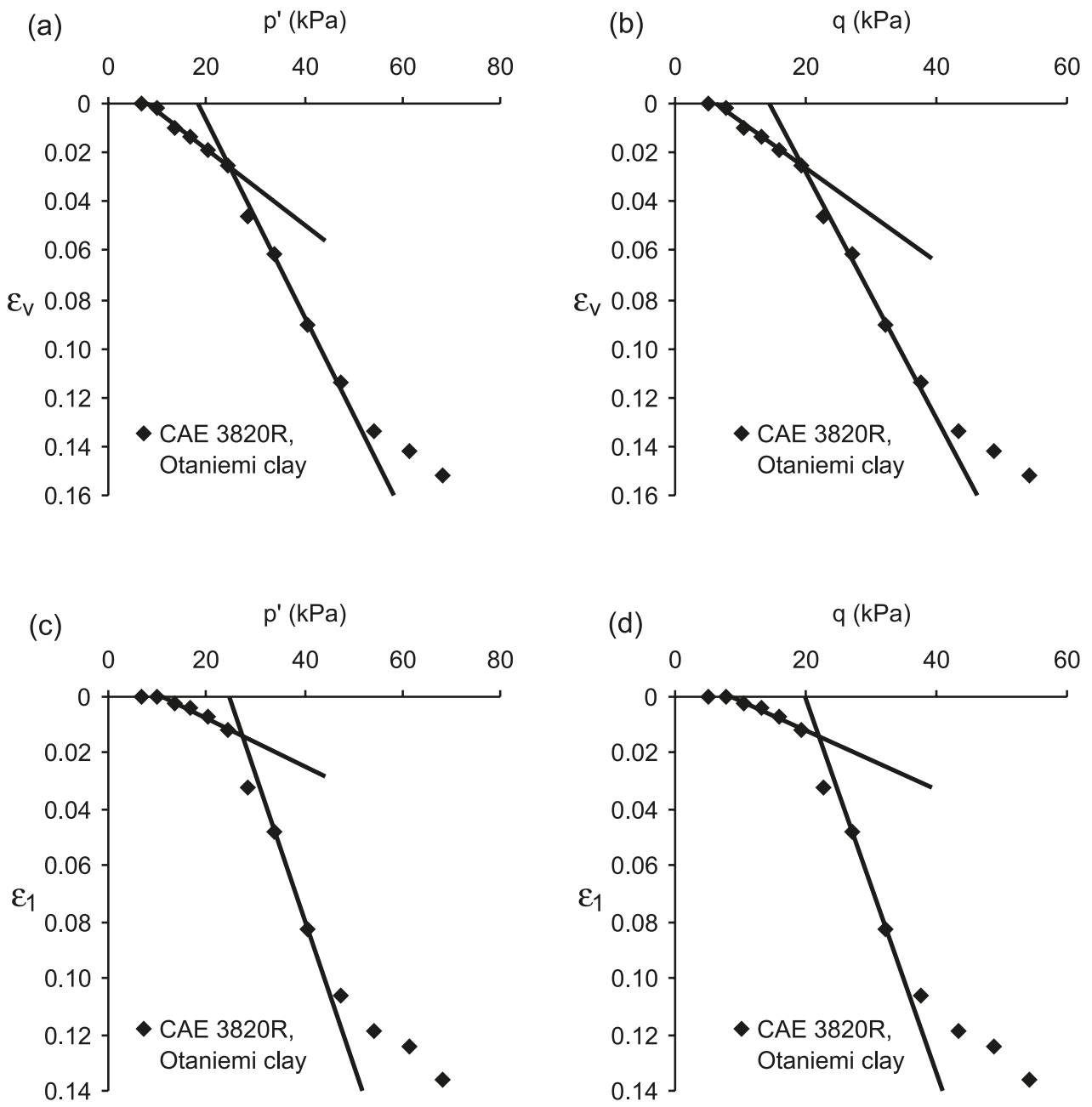

predicted by S-CLAY1 than MCC, which assumes an almost bilinear relationship $\ln p-\varepsilon_{\mathrm{v}}$ space. The shear strains are predicted extremely well with S-CLAY1 in the first loading stage (Fig. $7 b$ ) and reasonably well in the second stage. In contrast, MCC severely overestimates the shear strains in the first loading stage on triaxial compression and then slightly underestimates the shear strains in the second loading stage on triaxial extension. Therefore, the strain path is predicted very well by S-CLAY1 (Fig. 7c), whereas MCC predicts the strain gradients well only in the second loading stage.

In test CAE 3519R, the volumetric strains are predicted well with S-CLAY1, and the same applies to the yield stresses in both loading stages (Fig. 8a). In contrast, MCC underpredicts volumetric strains due to the unrealistic prediction of yield stresses. The shear strains (Fig. 8b) are predicted extremely well for both loading stages with SCLAY1, whereas MCC underpredicts the shear strains in the first loading stage and significantly overpredicts them in the second loading stage. The gradients of the strain path (Fig. 8c) are predicted rather well with both models.

In test CAE 3819R, which involved a first loading stage with a small negative stress ratio, both models underestimate the volumetric strains (Fig. 9a), MCC more significantly than S-CLAY1. This is partially a result of the selected value

for $\lambda$. The $\lambda$ values were chosen based on oedometer tests on reconstituted clay and, in this test, the gradients are clearly steeper than predicted. This could simply be due to variability between samples or could be attributed to trimming of the sample to the oedometer ring and (or) the friction between the sample and the ring. Even reconstituted samples can have some variability when they have been created from natural material, as samples from different batches may have minor variations in grain-size distribution and mineralogical composition which may affect the intrinsic properties. The sample in test CAE 3819R was from a different batch of samples compared to those in the previous tests.

In the first loading stage of test CAE 3819R, the yield point is predicted well with S-CLAY1, but significantly overestimated with MCC, which also overestimates the second yield point. The S-CLAY1 model predicts the volumetric strains well in the second loading stage $\left(\eta_{2}=0.77\right)$, whereas MCC overestimates the volumetric strains and, hence, ends up at the same total volumetric strain as $\mathrm{S}$ CLAY1. The S-CLAY1 model succeeds in predicting the shear strains (Fig. 9b), whereas MCC notably underestimates them in the first loading stage and significantly overestimates them in the second loading stage. The pattern of straining (Fig. 9c) is predicted better with S-CLAY1 than $\mathrm{MCC}$, especially in the second loading stage. 
Fig. 5. Test CAE 3216R on reconstituted Murro clay and S-CLAY1 model simulations using different $\mu$ values.

(a)

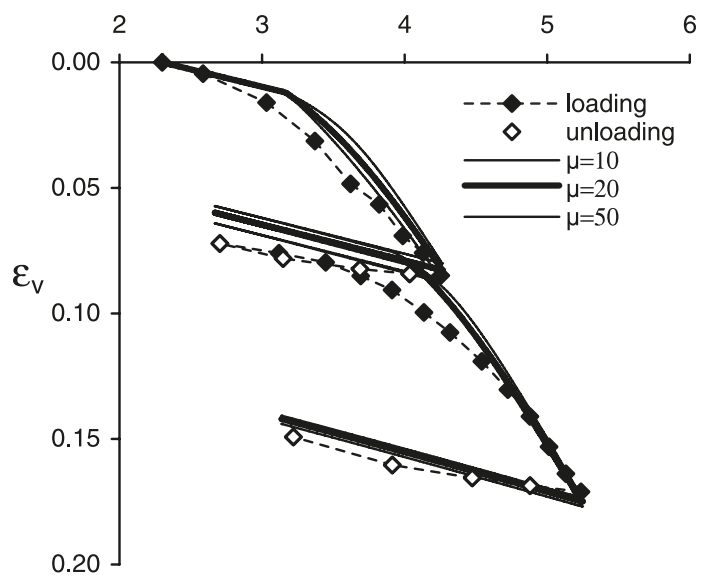

(b)

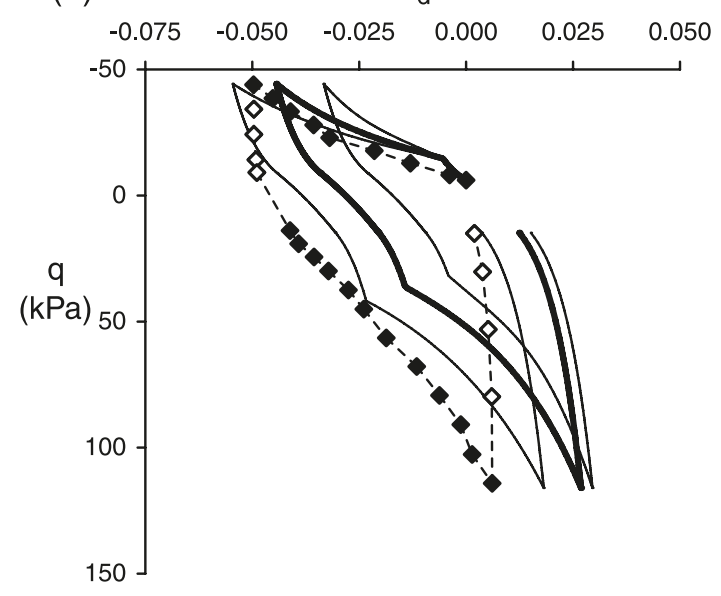

(c)

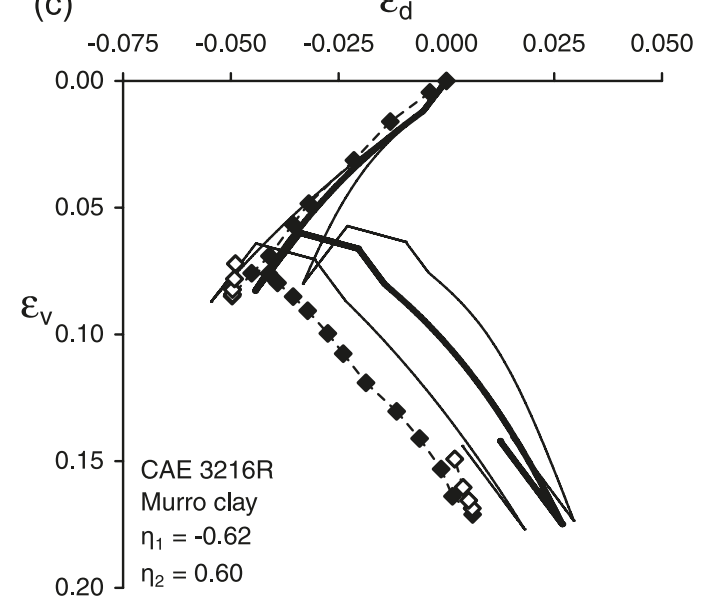

Both models, S-CLAY1 and MCC, underestimate similarly the volumetric strains in the first loading stage $\left(\eta_{1}=\right.$ 0.78) of test CAE 3820R (Fig. 10a). In the second loading stage $\left(\eta_{2}=-0.27\right)$, S-CLAY1 underestimates the volumetric strains slightly, but gives a good estimate of the yield point, whereas MCC underestimates the volumetric strains and significantly overestimates the yield stress. Again, the gradient
Fig. 6. Test CAE $3215 \mathrm{R}$ on reconstituted Murro clay and model simulations..

(a)

$\ln \mathrm{p}^{\prime}$

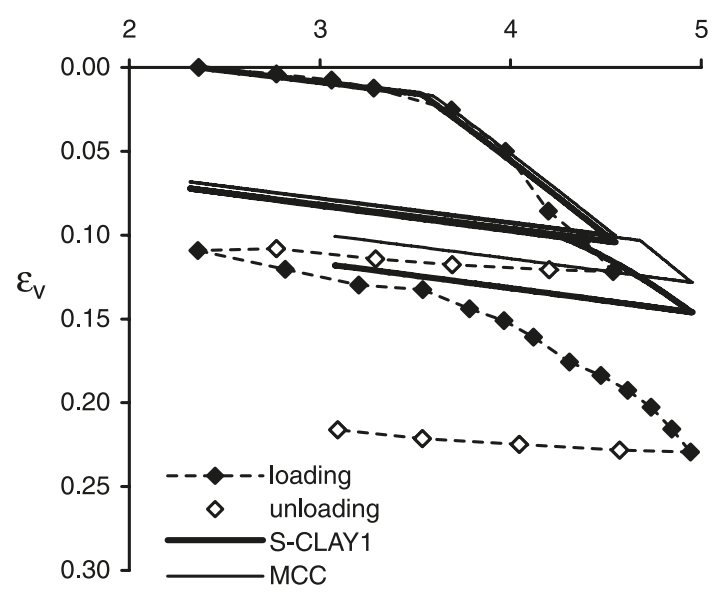

(b)
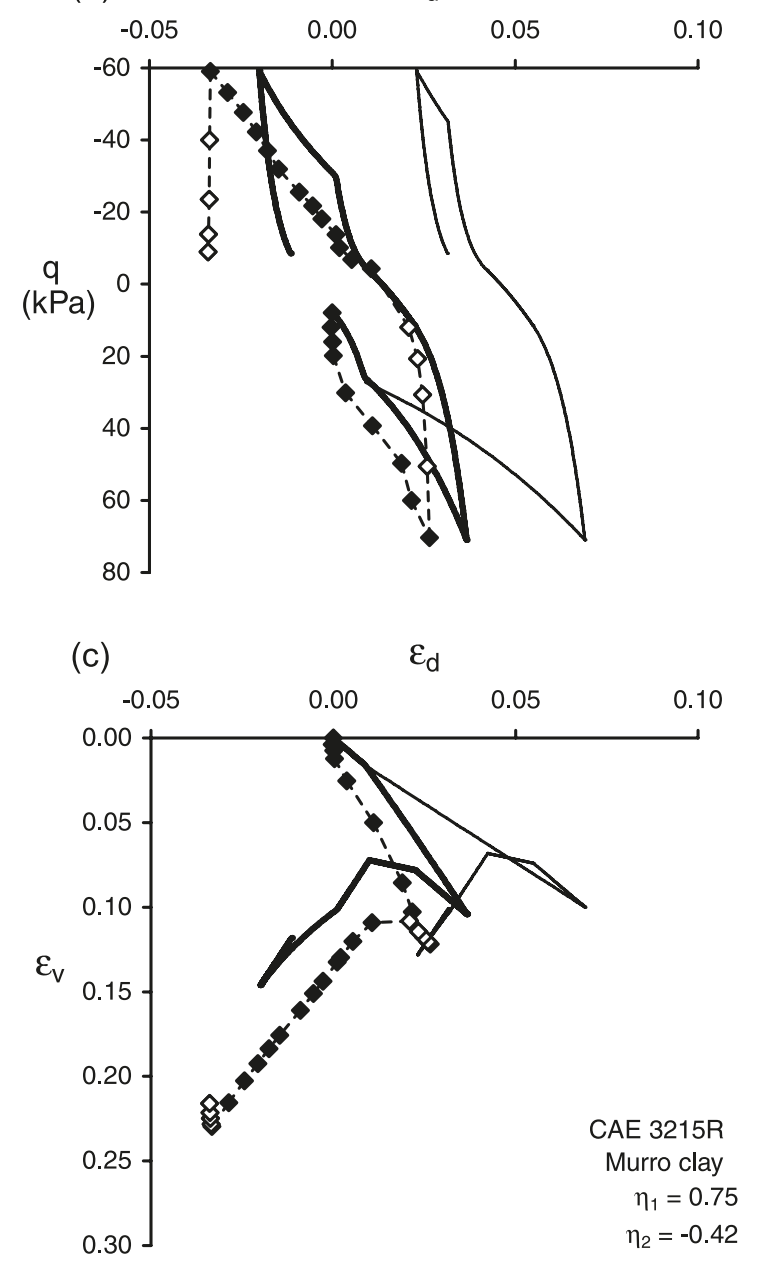

in the triaxial test appears to be steeper than assumed based on the oedometer tests. The sample for this test is from the same batch as that used in the previous test. The shear strains (Fig. 10b) are predicted satisfactorily with S-CLAY1, whereas MCC fails to predict them satisfactorily in both loading stages. The gradients of the strain path (Fig. 10c) are predicted rather well with S-CLAY1, but poorly with MCC, 
Fig. 7. Test CAE 3516R on reconstituted Otaniemi clay and model simulations.

(a)

In $\mathrm{p}^{\prime}$

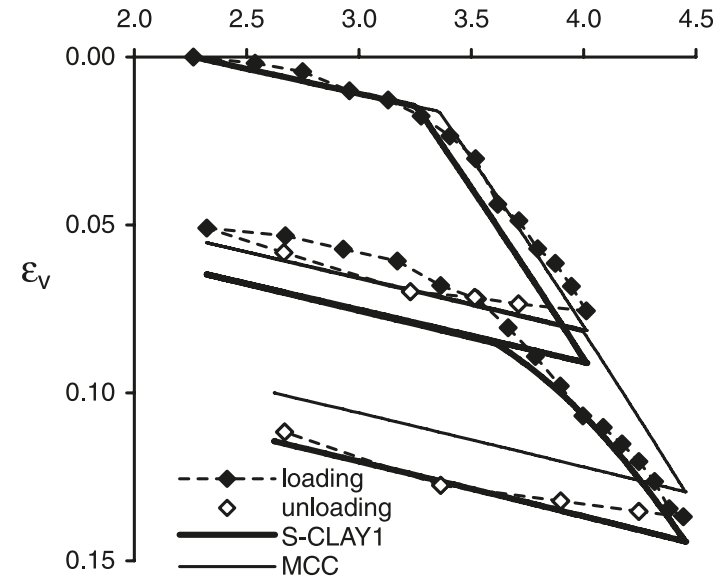

(b)

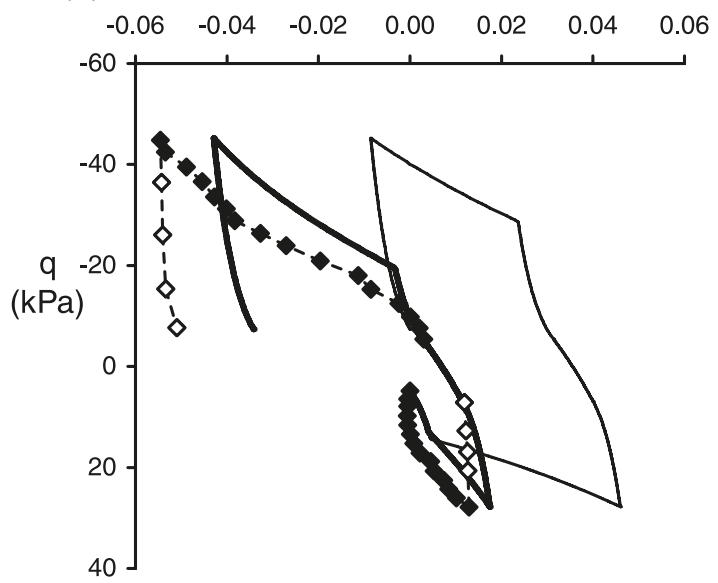

(c)

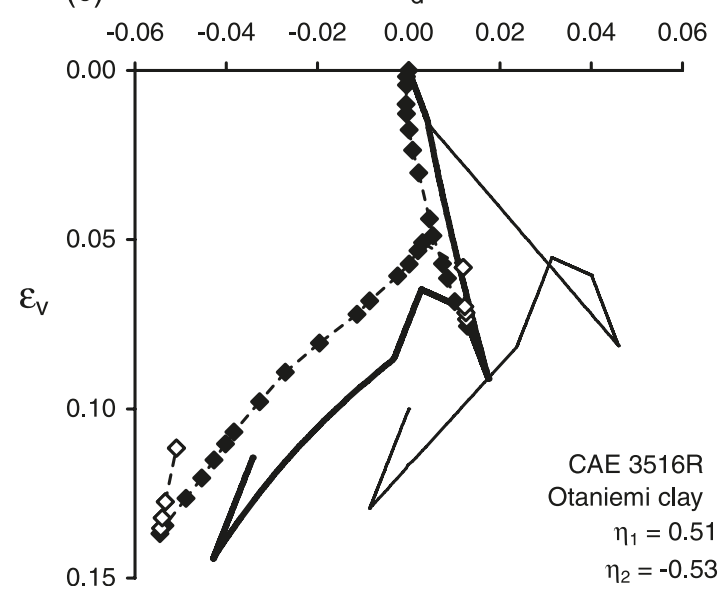

especially in the first loading stage. Overall, the results on reconstituted Otaniemi clay are comparable with those for reconstituted Murro and POKO clays (Koskinen et al. 2002b).

\section{Tests on reconstituted Vanttila clay}

Vanttila clay was the most sensitive in its natural state of the clays tested with very high natural water content. Conse-
Fig. 8. Test CAE 3519R on reconstituted Otaniemi clay and model simulations.

(a)

$\ln p^{\prime}$
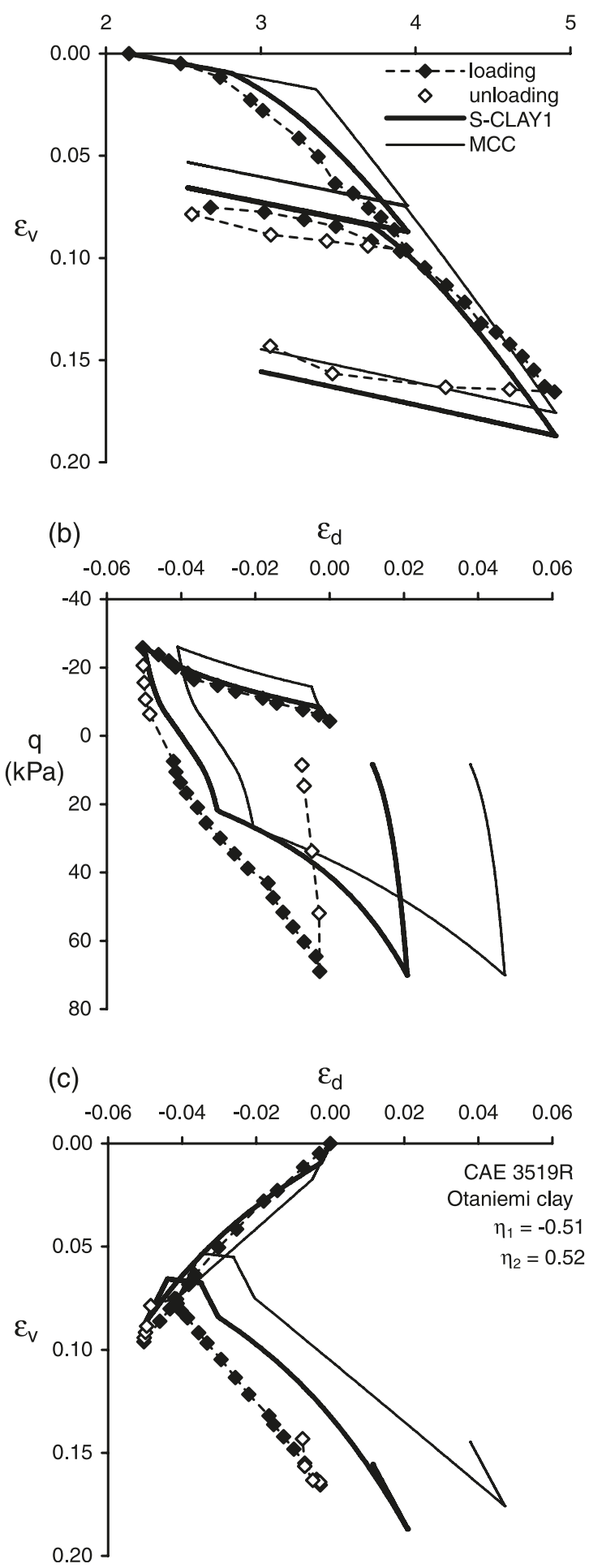

quently, the initial void ratios of the reconstituted samples (Table 3) were much lower than those of the clay in situ.

The S-CLAY1 model predicts extremely well the volumetric strains (Fig. 11a), yield stresses (Fig. 11a), and shear strains (Fig. 11b) in test CAE 3427R on reconstituted Vanttila clay in both loading stages $\left(\eta_{1}=-0.61\right.$ and $\left.\eta_{2}=0.40\right)$. Therefore, the gradients of the strain path (Fig. 11c) are also 
Fig. 9. Test CAE 3819R on reconstituted Otaniemi clay and model simulations.
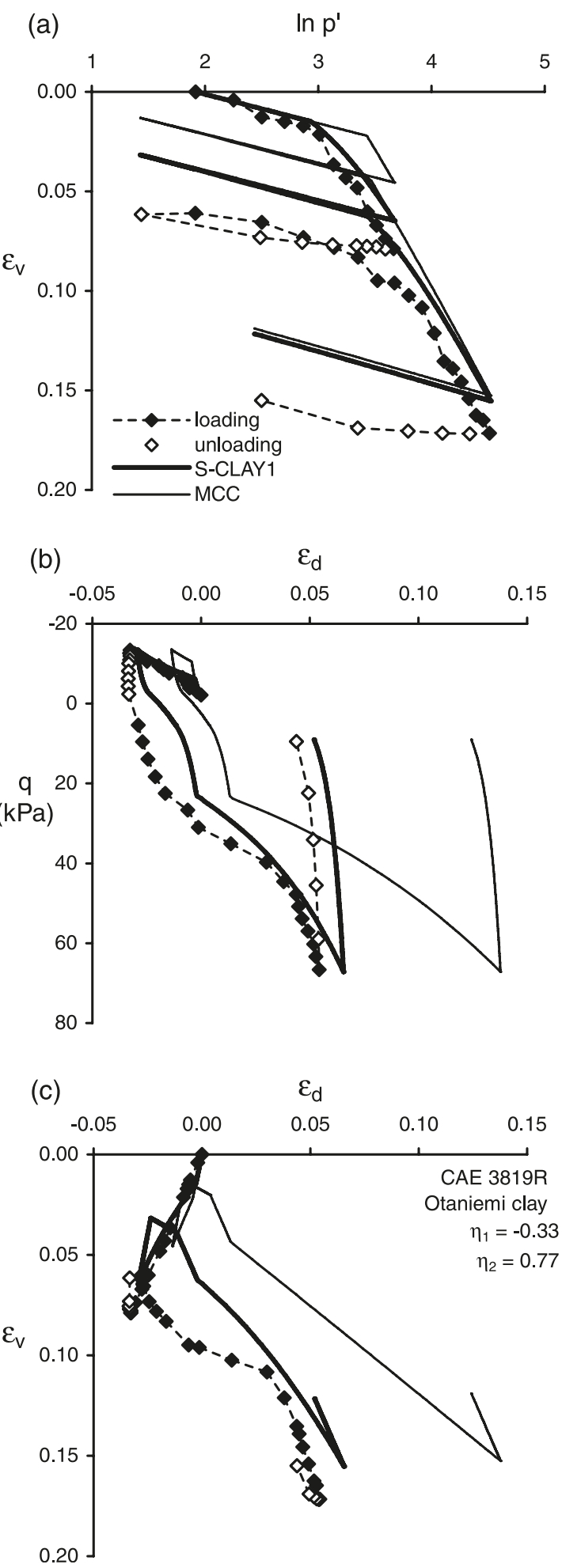

predicted very well with S-CLAY1. S-CLAY1 can also reproduce the shape of the volumetric stress-strain curve reasonably well, unlike MCC. For this particular test MCC also gives satisfactory strain predictions, despite failing to predict the yield stresses correctly.

The stress-strain response of test CAE 3429R predicted by the S-CLAY1 and MCC models is shown in Fig. 12.
Fig. 10. Test CAE 3820R on reconstituted Otaniemi clay and model simulations..
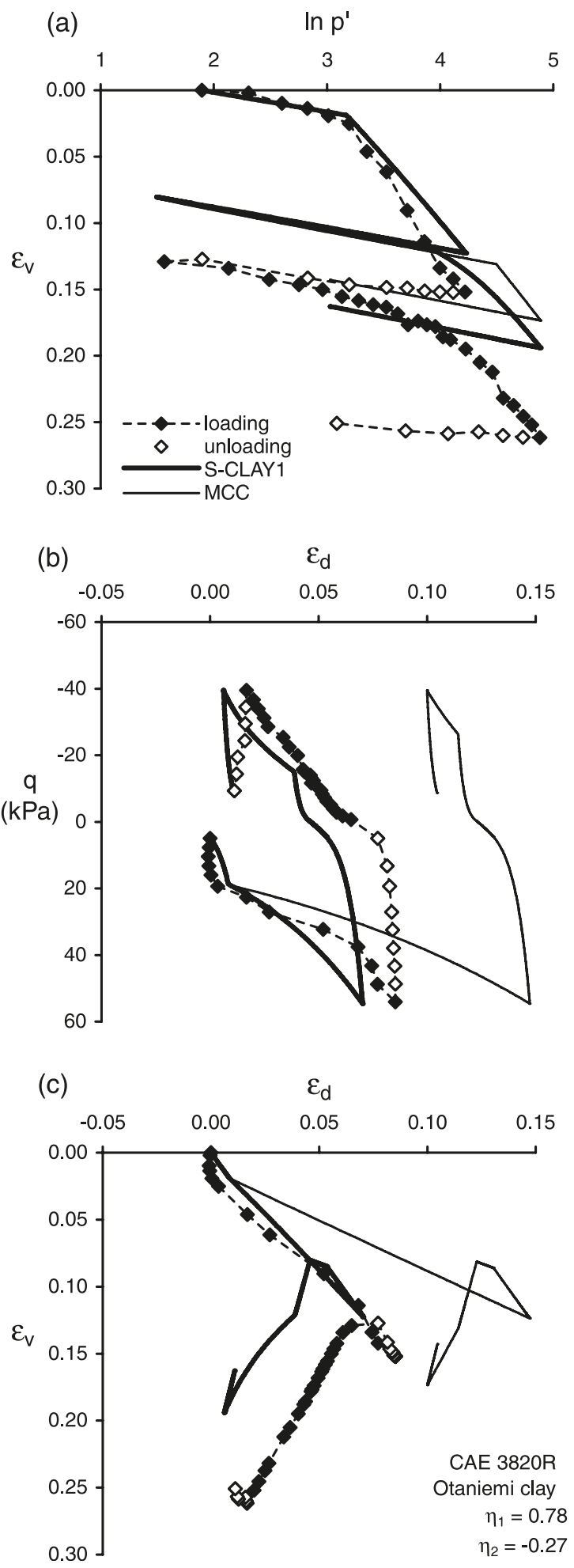

The volumetric strains (Fig. 12a) are slightly overpredicted in the first loading stage $\left(\eta_{1}=0.40\right)$ by both models, as they predict yielding too early. Volumetric strains in the second loading stage with $\eta_{2}=-0.61$ are predicted equally well by both models. S-CLAY1 underestimates the yield stresses in both loading stages and, in that regard, the MCC model performs better than S-CLAY1. However, the S-CLAY1 
model gives an excellent prediction of shear strains (Fig. 12), whereas the MCC model overestimates the shear strains in the first loading stage and gives a reasonable prediction in the second loading stage. The pattern of straining (Fig. 12c), therefore, is predicted much better by S-CLAY1 than by MCC, especially in the first loading stage. Overall, the results for reconstituted Vanttila clay confirm the comments made earlier.

\section{Conclusions and future work}

The S-CLAY1 model, which accounts for initial and plastic strain-induced anisotropy, has been applied to simulate the stress-strain behaviour of reconstituted Finnish clays along various stress paths in triaxial compression and triaxial extension. The materials chosen for testing cover a wide range of soft clays found in Scandinavia. In the reconstituted samples, the effect of bonding has been erased, but an anisotropic fabric has been recreated by an initial anisotropic consolidation stage. The values for the model parameters, with the exception of the elastic constants and parameter $\mu$ that controls the rate of rotation, were determined independently from the tests shown and have not been calibrated to give a good match. For comparison, the tests were also simulated with the isotropic modified Cam clay (MCC) model.

The results demonstrate that plastic anisotropy is a significant feature of soil behaviour even when dealing with reconstituted clays. Only an anisotropic model is able to predict yielding correctly when stress path directions change from the stress path the soil experienced in the past. The SCLAY1 model generally gives very good predictions of yield stresses and strains. The shapes of the stress-strain curves were also well reproduced by the model. The SCLAY1 model predicted the volumetric strains with reasonable accuracy, although in some cases they were slightly underestimated. This underestimation can be attributed to the creep effects in some cases, as the duration for some load increments, due to practical reasons, was longer than desired. The model in its current version does not account for creep. Recently, Vermeer and his co-workers (Vermeer et al. 2006; Leoni et al. 2007) have extended the model to incorporate creep. Furthermore, some results suggest steeper compression gradients in triaxial tests than predicted by the $\lambda$ values estimated from oedometer tests. This discrepancy was most notable for Otaniemi clay, which had the greatest variation in the values for the initial void ratio. Part of the discrepancy in volumetric strain values between the tests may be due to natural variability (as samples were produced in small batches) and (or) sample trimming procedures (oedometer versus triaxial).

The S-CLAY1 model predicted the shear strains with very good accuracy when assuming $\mu$ values that correspond to the empirical correlations by Zentar et al. (2002). Generally, the gradients of the strain paths were predicted well with SCLAY1, confirming the appropriateness of the associated flow rule in the S-CLAY1 model. The successful predictions of yield stresses and shear straining also confirm that the particular form of the rotational hardening law in the SCLAY1 model (eq. [3]) is appropriate. In contrast, the MCC model often performed poorly in predicting the stress-strain behaviour of the reconstituted clays. This is
Fig. 11. Test CAE 3427R on reconstituted Vanttila clay and model simulations.
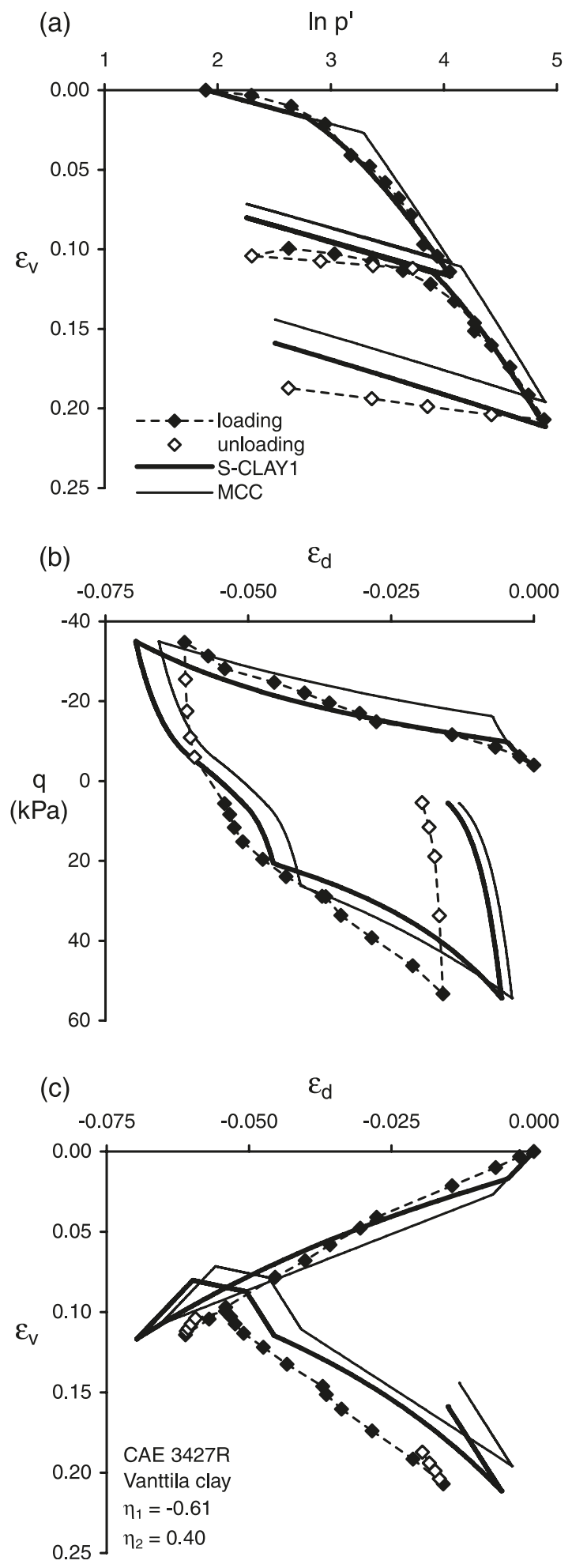

also true for natural clays. As shown by Karstunen et al. (2005) based on simulations of the Murro test embankment, predictions by the S-CLAY1 model are much closer to the field measurements than the predictions by the MCC model.

The results in this paper demonstrate that accounting for anisotropy in the manner of the S-CLAY1 model signifi- 
Fig. 12. Test CAE 3429R on reconstituted Vanttila clay and model simulations and test data.
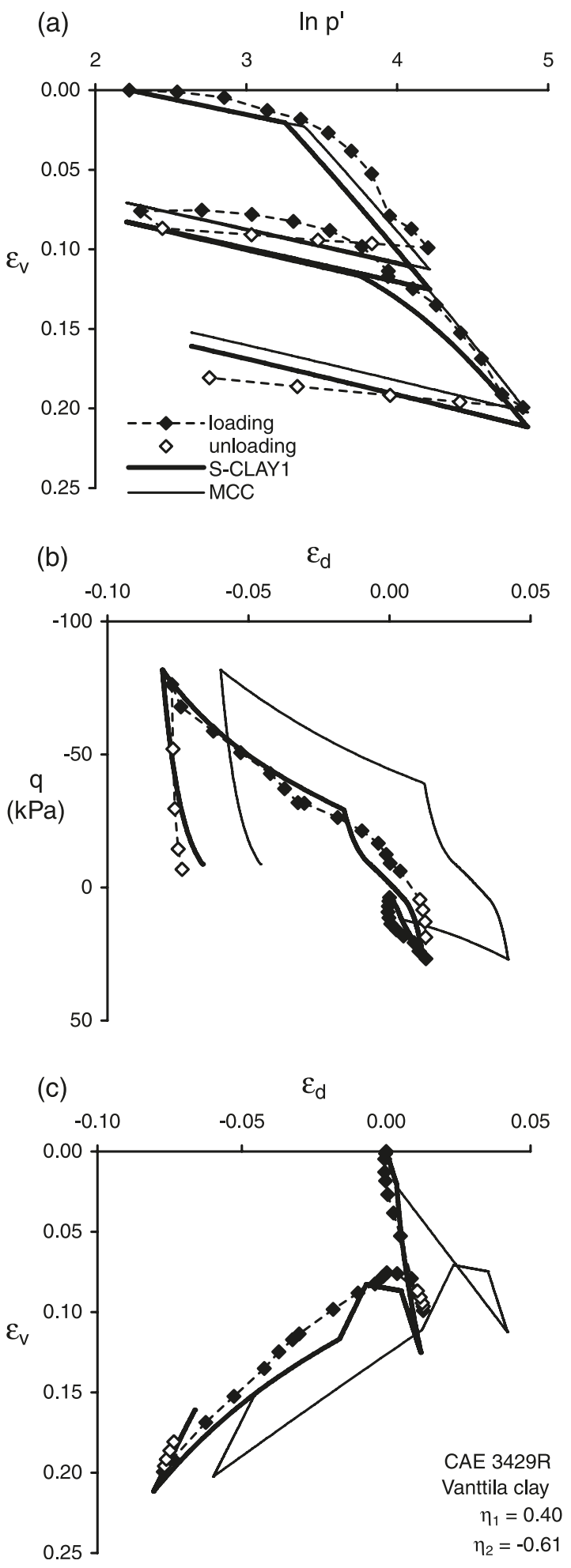

cantly improves the accuracy of model predictions for reconstituted (unstructured) soft clays. Because the values of the parameters for the S-CLAY1 model can be estimated based on the same tests as required for the application of the MCC model, the S-CLAY1 model has great potential for practical use. When dealing with natural soils, it may also be necessary to account for the effect of interparticle bonding and subsequent degradation of bonding due to plastic straining (destructuration), when dealing with very sensitive clays. The S-CLAY1 model has already been extended to account for the effects of destructuration (see Koskinen et al. 2002a). Finite element simulations of the Murro test embankment (Karstunen et al. 2005) suggest that the effect of bonding and destructuration is often averaged out in a typical geotechnical boundary value problem and the S-CLAY1 model gives reasonable predictions provided that the value for the slope of the normal compression line corresponds to $K_{0}$ loading.

\section{Acknowledgements}

The work presented was carried out as part of a Research Training Network on "Soft clay modelling for engineering practice" (grant HPRN-CT-1999-00049) and a Marie Curie Research Training Network on "Advanced modelling of ground improvement on soft soils" (contract No. MRTNCT-2004-512120) supported by the European Community. The experimental programme was funded by the Academy of Finland (grants 40702, 53936, and 210744) and by the Finnish Road Administration. The authors would like to thank Prof. Simon Wheeler (University of Glasgow) and Dr. Rachid Zentar (École des Mines de Douai) for useful comments during the work.

\section{References}

Atkinson, J.H., Richardson, D., and Robinson, P.J. 1987. Compression and extension of $K_{0}$ normally consolidated kaolin clay. Journal of Geotechnical Engineering (ASCE), 113: 1468-1482.

Banerjee, P.K., and Yousif, N.B. 1986. A plasticity model for the mechanical behaviour of anisotropically consolidated clay. International Journal for Numerical and Analytical Methods in Geomechanics, 10: 521-541. doi:10.1002/nag.1610100505.

Banerjee, P.K., Kumbhojkar, A.S., and Yousif, N.B. 1988. Finite element analysis of the stability of a vertical cut using an anisotropic soil model. Canadian Geotechnical Journal, 25: 119-127.

Burland, J.B. 1990. On the compressibility and shear strength of natural clays. Géotechnique, 40: 329-378.

Dafalias, Y.F. 1986. An anisotropic critical state soil plasticity model. Mechanics Research Communications, 13: 341-347. doi:10.1016/0093-6413(86)90047-9.

Dafalias, Y.F., Manzari, M.T., and Papadimitriou, A.G. 2006. SANICLAY: simple anisotropic clay plasticity model. International Journal for Numerical and Analytical Methods in Geomechanics, 30: 1231-1257. doi:10.1002/nag.524.

Davies, M.C.R., and Newson, T.A. 1993. A critical state constitutive model for anisotropic soils. In Predictive soils mechanics. Edited by G.T. Houlsby and A.N. Schofield. Thomas Telford, London, UK. pp. 219-229.

Huang, M., and Wei, X. 2007. An anisotropic bounding surface model for natural clays. In Proceedings of International Workshop on Constitutive Modelling - Development, Implementation, Evaluation and Application, 12-13 January 2007, Hong Kong Edited by H. Yin, X.S. Li, A.T. Yeung, and C.S. Desai. Advanced Technovation Limited, Hong Kong, pp. 317-326.

Karstunen, M., and Koskinen, M. 2004a. Anisotropy and destructuration of Murro clay. In Advances in Geotechnical Engineering: The Skempton Memorial Conference, London, UK, 29-31 March 2004. Edited by R.J. Jardine, D.M. Potts and K.G. Higgins. Thomas Telford, London, UK. Vol. 1, pp. 476-487. 
Karstunen, M., and Koskinen, M. 2004b. Undrained shearing of soft structured natural clays. In Proceedings of 9th International Symposium on Numerical Models in Geomechanics (NUMOG IX), Ottawa, Ont., 25-27 August 2004. A.A. Balkema, Leiden, the Netherlands. pp. 173-179.

Karstunen, M., Krenn, H., Wheeler, S.J., Koskinen, M., and Zentar, R. 2005. The effect of anisotropy and destructuration on the behaviour of Murro test embankment. International Journal of Geomechanics, 5(2): 87-97. doi:10.1061/(ASCE)1532-3641 (2005)5:2(87).

Kirkgard, M.M., and Lade, P.V. 1993. Anisotropic three-dimensional behavior of a normally consolidated clay. Canadian Geotechnical Journal, 30: 848-858. doi:10.1139/cgj-30-5-848.

Koskinen, M., and Karstunen, M. 2004. The effect of structure on the compressibility of Finnish clays. In Proceedings of the 14th Nordic Geotechnical Meeting (NGM 2004), Ystad, Sweden, 1921 May 2004. Swedish Geotechnical Society, Linkoping, Sweden. Report 3:2004, Vol. 1. pp. A-11-A-22.

Koskinen, M., Karstunen, M., and Wheeler, S.J. 2002a. Modelling destructuration and anisotropy of a soft natural clay. In Proceedings of the 5th European Conference on Numerical Methods in Geotechnical Engineering, Paris, 4-6 September 2002. Edited by Ph. Mestat. Presses de 1'ENPC/LCPC, Paris. pp. 11-20.

Koskinen, M., Zentar, R., and Karstunen, M. 2002 $b$. Anisotropy of reconstituted POKO clay. In Proceedings of the 8th International Symposium on Numerical Models in Geomechanics (NUMOG), Rome, Italy, 10-12 April 2002. Edited by G.N. Pande and S. Pietruszczak. A.A. Balkema, Lisse, the Netherlands. pp. 99-105.

Koskinen, M., Karstunen, M., and Lojander, M. 2003. Yielding of "ideal" and natural anisotropic clays. In Proceedings of the International Workshop on Geotechnics of Soft Soils - Theory and Practice, Noordwijkerhout, the Netherlands, 17-19 September 2003. Edited by P.A. Vermeer, H.F. Schweiger, M. Karstunen, and M. Cudny. VGE, Essen. pp. 197-204.

Leoni, M., Vermeer, P.A., and Yu, X. 2007. A new anisotropic model for creep in soft soils. In International Workshop on Constitutive Modelling-Development, Implementation, Evaluation and Application. Edited by H Yin, X.S. Li, A.T. Yeung, and C.S. Desai. Hong Kong, China. 12-13 January 2007. Advanced Technovation Limited, Hong Kong. pp. 409-414.

Messerklinger, S., Kahr, G., Plötze, M., Giudici Trausch, J., Springman, S.M., and Lojander, M. 2003. Mineralogical and mechanical behaviour of soft Finnish and Swiss clays. In Pro- ceedings of the International Workshop on Geotechnics of Soft Soils-Theory and Practice, Noordwijkerhout, the Netherlands, 17-19 September 2003. Edited by P.A. Vermeer, H.F. Schweiger, M. Karstunen, and M. Cudny. VGE, Essen, Germany. pp. 467-472.

Nova, R. 1985. Mathematical modelling of anisotropic clays. In Proceedings of the 11th International Conference on Soil Mechanics and Foundation Engineering, San Francisco, Calif., 12-16 August 1985. A.A. Balkema, Rotterdam, Vol. 1, pp. 607-611.

Pestana, J.M., and Whittle, A.J. 1999. Formulation of a unified constitutive model for clays and sands. International Journal for Numerical and Analytical Methods in Geomechanics, 23(12): 1215-1243. doi:10.1002/(SICI)1096-9853(199910)23:12<1215:: AID-NAG29>3.0.CO;2-F.

Roscoe, K.H., and Burland, J.B. 1968. On the generalized stressstrain behaviour of "wet" clay. In Engineering plasticity. Edited by J. Heyman and F.A. Leckie. Cambridge University Press. London, UK. pp. 553-569.

Vermeer, P.A., Leoni, M., Karstunen, M., and Neher, H. 2006. Modelling and numerical simulations of creep in soft soils. Invited keynote paper. In Proceedings of 4th International Conference on Soft Soil Engineering, Vancouver, B.C., 4-6 October 2006. Edited by D. Chan and K.Tim Law. Taylor Frances, Leiden, the Netherlands. pp. 57-71.

Wheeler, S.J., Näätänen, A., Karstunen, M., and Lojander, M. 2003. An anisotropic elasto-plastic model for soft clays. Canadian Geotechnical Journal, 40: 403-418. doi:10.1139/t02-119.

Whittle, A.J., and Kavvadas, M.J. 1994. Formulation of MIT-E3 constitutive model for overconsolidated clays. Journal of Geotechnical Engineering, ASCE, 120(1): 173-198. doi:10.1061/ (ASCE)0733-9410(1994)120:1(173).

Zentar, R., Karstunen, M., and Wheeler, S.J. 2002. Influence of anisotropy and destructuration on undrained shearing of natural clays. In Proceedings of the 5th European Conference on $\mathrm{Nu}-$ merical Methods in Geotechnical Engineering, Paris, 4-6 September 2002. Edited by $\mathrm{Ph}$. Mestat. Presses de l'ENPC/LCPC, Paris. pp. 21-26.

Zhou, C., Yin, J.-H., Zhu, J.-G., and Cheng, C.-M. 2006. Elastic anisotropic viscoplastic modelling of the strain-rate dependent stress-strain behaviour of $K_{0}$-consolidated natural marine clays in triaxial shear test. International Journal of Geomechanics, 5(3): 218-232. 